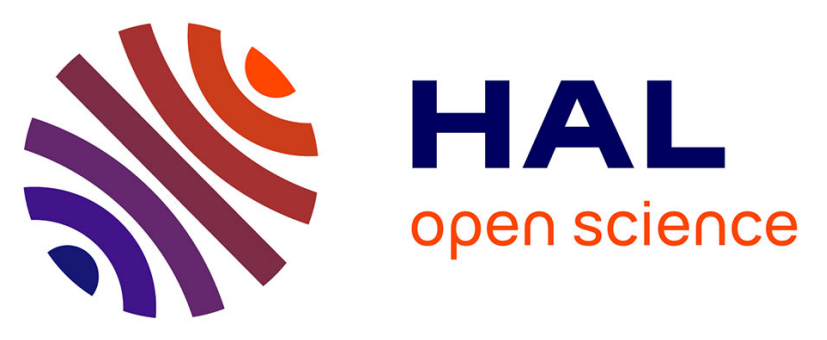

\title{
Investigation of the mechanism(s) controlling microwave sintering of alpha-alumina: Influence of the powder parameters on the grain growth, thermodynamics and densification kinetics
}

Fei Zuo, Sébastien Saunier, Sylvain Marinel, Pauline Chanin-Lambert, Nathalie Peillon, Dominique Goeuriot

\section{To cite this version:}

Fei Zuo, Sébastien Saunier, Sylvain Marinel, Pauline Chanin-Lambert, Nathalie Peillon, et al.. Investigation of the mechanism(s) controlling microwave sintering of alpha-alumina: Influence of the powder parameters on the grain growth, thermodynamics and densification kinetics. Journal of the European Ceramic Society, 2015, 35 (3), pp.959-970. 10.1016/j.jeurceramsoc.2014.10.025 . emse-01145446

\author{
HAL Id: emse-01145446 \\ https://hal-emse.ccsd.cnrs.fr/emse-01145446
}

Submitted on 27 Aug 2021

HAL is a multi-disciplinary open access archive for the deposit and dissemination of scientific research documents, whether they are published or not. The documents may come from teaching and research institutions in France or abroad, or from public or private research centers.
L'archive ouverte pluridisciplinaire HAL, est destinée au dépôt et à la diffusion de documents scientifiques de niveau recherche, publiés ou non, émanant des établissements d'enseignement et de recherche français ou étrangers, des laboratoires publics ou privés. 


\title{
Investigation of the mechanism(s) controlling microwave sintering of $\alpha$-alumina: Influence of the powder parameters on the grain growth, thermodynamics and densification kinetics
}

\author{
Fei Zuo $^{\mathrm{a}, 1}$, Sébastien Saunier ${ }^{\mathrm{a}, *}$, Sylvain Marinel $^{\mathrm{b}}$, Pauline Chanin-Lambert ${ }^{\mathrm{a}}$, \\ Nathalie Peillon ${ }^{\mathrm{a}}$, Dominique Goeuriot ${ }^{\mathrm{a}}$ \\ ${ }^{a}$ Centre Sciences des Matériaux et des Structures, CNRS-UMR 5307, Ecole Nationale Supérieure des Mines de St-Etienne, 42023 St-Etienne, France \\ ${ }^{\mathrm{b}}$ Laboratoire de Cristallographie et Sciences des Matériaux, CNRS-UMR 6508, ENSICAEN, 14050 Caen, France
}

\begin{abstract}
The objective of this investigation is to deepen the understanding of the mechanism(s) involved in densification and grain growth underlying microwave sintering of $\alpha$-alumina. The densification behavior and microstructure evolution of $\alpha$-alumina powders with different $\mathrm{MgO}$ doping levels as well as specific surface areas have been systematically and quantitatively studied during conventional and $2.45 \mathrm{GHz}$ microwave multimode sintering. It is shown that the microwave-induced favorable effects on densification could be more important due to the existence of $\mathrm{MgO}$ dopant or a decrease of particle size. Combined with the thermodynamics and kinetics considerations, one assumed that grain-boundary diffusion could be significantly enhanced by microwave non-thermal effect. In addition, the grain growth retardation effect has been attributed to the fine porosity retention induced by microwave electromagnetic field, but not to the local over-heating at grain boundaries.
\end{abstract}

Keywords: Microwave sintering; $\alpha-\mathrm{Al}_{2} \mathrm{O}_{3}$; Grain growth; Thermodynamics; Kinetics

\section{Introduction}

In recent years, microwave energy has been successfully applied as a heating source for processing different kinds of ceramic materials. ${ }^{1-4}$ In general, compared with conventional heating techniques, microwave sintering has a high potential to reduce the processing time as well as temperature, and to optimize functional properties. The so-called "microwave effect" seems widely accepted as a plausible reason for these advantages. However, the detailed explanation of this enhanced effect on sintering is still under debate. Among them, two main

\footnotetext{
* Corresponding author. Tel.: +33 477420225 ; fax: +33 477420249. E-mail address: saunier@emse.fr (S. Saunier).

${ }^{1}$ Present address: French National Centre for Scientific Research (CEMHTIUPR3079), 45071 Orléans, France.
}

views are frequently mentioned: non-thermal effect and local thermal effect. Non-thermal effect underlying microwave sintering is interpreted by Rybakov et al. ${ }^{5}$ in view of the effect of the ponderomotive force. They suggest that in microwave process, a coherent electromagnetic field drives an oscillatory motion of the charged particles, which can induce an additional driving force for mass transport in solids. In contrast to this microwave field non-thermal theory, the concept of local thermal effect, proposed by Raj et al. ${ }^{6}$, is based on the local Joule heating at the grain boundaries under electrical field due to the high dielectric loss and electrical resistance of grain boundaries. They suggest that the higher temperature in grain-boundary regions relative to the bulk region leads to retard the grain growth and to enhance the densification rate.

Alumina is a widely used ceramic. Therefore, this material is frequently selected as a model material to investigate 
the process techniques, including the microwave based processes. $^{7-10}$ About the macroscopic advantages of microwave sintering of alumina, the literature is very rich. ${ }^{11-14}$ Nevertheless, the majority of these experimental investigations mostly focused on phenomenological level because neither systematic comparison nor quantitative assessment of the microwave effect on densification and/or microstructure evolution has been accomplished. Beyond any doubt, each phenomenological observation and study is meaningful to a common understanding of the microwave enhancement. However, it is really difficult to compare and discuss the results through different studies, as those studies have been conducted in various dispersed ways. One of the most important questions is how to use this promising method to fabricate new or improved materials at industrial scale so that this technique could become an alternative route over conventional methods. This question still remains unanswered. The answer must lie in a deep understanding of this process at a more fundamental level, such as the microstructure evolution, the sintering thermodynamics and densification kinetics approaches. Moreover, these fundamental approaches should be undertaken by modifying the factors which seem most likely to affect the microwave effect.

The structural non-uniformities in solids such as grain boundaries always have an important influence on the accelerated densification and grain growth retardation..$^{5,6}$ For this reason, the particle size of alumina powders, which contributes to the concentration of grain boundaries, should be selected as a factor to study. Additionally, as we know, dopant is widely used into sintering systems so as to improve the sinterability and/or final properties of samples. Nevertheless, study about the influence of dopant on microwave sintering is rarely reported in the literature. According to a recent result demonstrated by Zuo et al. ${ }^{15}$, the presence of $\mathrm{MgO}$ as a dopant in alumina was beneficial for microwave enhancement on densification. However, it still remains the question regarding the effect of dopant on microstructure evolution under microwave field. In this sense, the doping level should be another interesting factor in the investigation of microwave sintering process.

Taking into account those issues, the purpose of the present work is to systematically investigate the influence of several alumina powder parameters (particle size and $\mathrm{MgO}$ doping level) on the microstructure evolution, sintering thermodynamics and densification kinetics during microwave sintering. Simultaneously, comparative studies were rigorously achieved in conventional sintering. Based on this research, we have attempted to formulate hypotheses concerning the mechanism(s) controlling densification and grain growth during the microwave sintering of $\alpha$-alumina. It will be meaningful to develop the indepth understanding of the microwave sintering process at both the fundamental and the applied levels.

\section{Experimental procedures}

\subsection{Temperature measurement and calibration procedure}

Temperature is a key thermal parameter during the research of microwave sintering process. In the literature, temperature measurement methods used in a microwave environment can be mainly categorized into two routes: thermocouples and infrared pyrometers. As a contact measurement technique, thermocouples are commonly used in conventional heating systems due to their good measurement accuracy. However, the presence of a thermocouple in a microwave cavity can lead to local electromagnetic field distribution changes, and as a consequence, some local thermal gradient can develop within the sample. ${ }^{16}$ In this sense, the infrared pyrometer, as used in the majority of studies, is a much more appropriate temperature measurement technique in microwave environment. Nevertheless, inaccurate or incomplete temperature measurements still challenge the investigation of microwave processes. We must note that in the literature, the calibration of temperature measurement for radiation pyrometer was rarely mentioned. ${ }^{16,17}$

In this work, two infrared pyrometers (5G-1007 and 5R-3015, IRCON, USA) were used as temperature measurement devices. The monochromatic pyrometer 5G-1007 determines the temperature $T$ from 250 to $1000^{\circ} \mathrm{C}$ on account of a value of emissivity $\varepsilon(\lambda, T)$ at one wavelength $\lambda$. The bichromatic pyrometer $5 \mathrm{R}$ 3015 measures the temperature from 700 to $1800^{\circ} \mathrm{C}$ by detecting the intensities at two wavelengths $\lambda_{1}$ and $\lambda_{2}$ and consequently this determination can be performed without the knowledge of emissivity when the slope of emissivity " $\varepsilon$-slope" is known. In addition, we have largely improved the calibration method. The innovations were mainly embodied in the selection of the temperature range and the analog of the real processing conditions. With regard to the calibration temperature range, we have paid close attention to the range $\left[900-1560^{\circ} \mathrm{C}\right]$ in which the sintering of $\alpha$-alumina occurs, on the basis of the melting points of germanium $\left(\mathrm{Ge}, 938^{\circ} \mathrm{C}\right)$ and palladium $\left(\mathrm{Pd}, 1555^{\circ} \mathrm{C}\right)$. This temperature range is within the measuring range of the pyrometer 5R-3015. Therefore, this calibration was principally for the " $\varepsilon$-slope" in bichromatic mode. Concerning the analog of the real processing conditions, we have carried out the calibrations under exactly the same conditions as in all real experiments: in the presence of susceptor $\mathrm{SiC}$, in the same insulation configuration, using the same heating rates and microwave power. Thanks to these improvements compared with the calibrations reported in the literature, a reliable temperature measurement in microwave sintering has been achieved.

In conclusion, by using three different heating rates $(2,25$ and $100^{\circ} \mathrm{C}$ ) as well as two references ( $\mathrm{Ge}$ and $\mathrm{Pd}$ ), the average apparent " $\varepsilon$-slope" value at the temperatures of 938 and $1555^{\circ} \mathrm{C}$ was $1.0092 \pm 0.0147$. If we used the expected " $\varepsilon$-slope" value " 1 ", the temperature measurement error between these two melting points was $11 \pm 5^{\circ} \mathrm{C}$. However, note that this measured temperature is only at the surface of a sample. It may cause inaccurate measurement of temperature due to the variation of coupling capability of alumina with electromagnetic field as temperature is increasing, especially at high heating rates. In order to better understand temperature difference between surface and interior during microwave heating, the grain size distribution throughout the bulk of a sintered sample at $100^{\circ} \mathrm{C} / \mathrm{min}$ was analyzed by using SEM micrographs of polished and thermally etched cross-sections. According to the grain size distribution in Fig. 1, it shows a homogenous grain size throughout the 


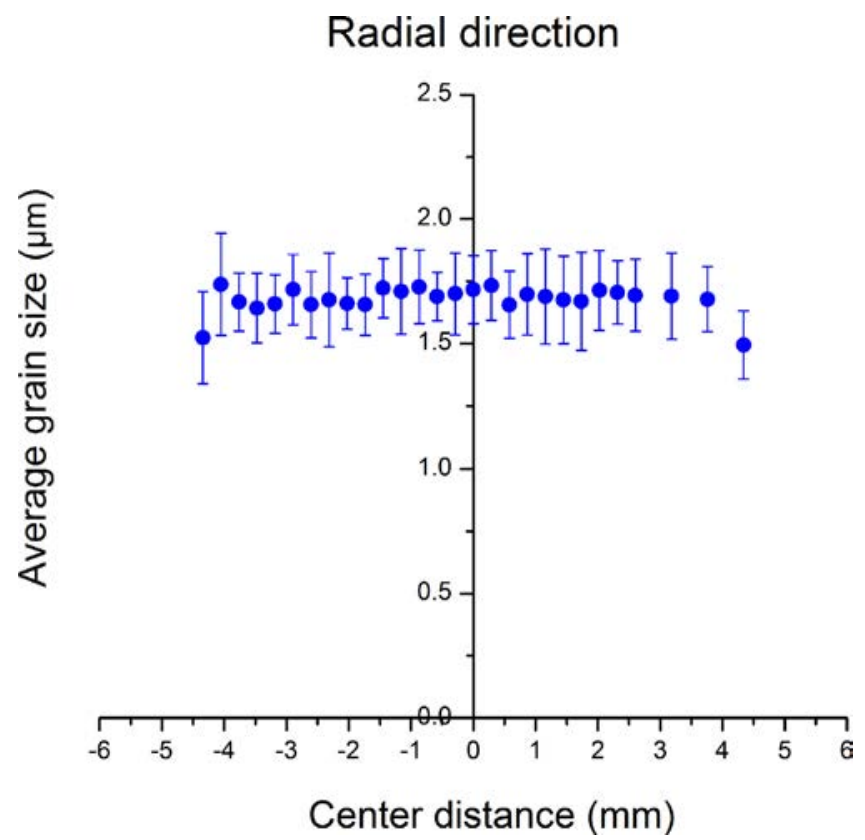

Fig. 1. Grain size distribution throughout the microwave-sintered A19 alumina sample along the radial direction. Sintering was performed at $100{ }^{\circ} \mathrm{C} / \mathrm{min}$ to $1450{ }^{\circ} \mathrm{C}$ and held at this temperature for $5 \mathrm{~min}$. The relative density was $99.45 \%$. The relative lower values on each side only correspond to a relaxation of the initial density of compact after uniaxial pressing.

alumina sample, indicating a homogenous temperature distribution during microwave heating process.

\subsection{Starting powders and consolidation of green samples}

High purity commercial $\alpha$-alumina powders (Baikalox, Baikowski International, France), pure or $\mathrm{MgO}$-doped, were selected as starting materials in this study. The details of these powders are given in Table 1 , where $\mathrm{MgO}$ and $S_{\mathrm{BET}}$ are respectively, amount of $\mathrm{MgO}$ dopant and specific surface area. In view of Table 1, four types of alumina powder can be divided into two series: A6, A6-500 and A6-4000 powders have the same particle size but different doping amounts, in order to investigate the influence of $\mathrm{MgO}$ dopant on the microwave sintering; $\mathrm{A} 6$ and A19 powders are magnesia free, but have different particle sizes, for the purpose of understanding the effect of particle size on microwave sintering.

The starting powders were uniaxially pressed into disks (12 $\mathrm{mm}$ diameter $\times 4 \mathrm{~mm}$ thickness for microwave sintering and
$8 \mathrm{~mm}$ diameter $\times 4.5 \mathrm{~mm}$ thickness for conventional sintering) at pressures from 380 to $400 \mathrm{MPa}$, in order to achieve a similar green density and to increase the comparability among the different samples. The organic compound was removed by heating at $2{ }^{\circ} \mathrm{C} / \mathrm{min}$ to $600{ }^{\circ} \mathrm{C}$ with a dwell of $1 \mathrm{~h}$ in air, and the average density of green bodies after this process was $52.1 \pm 0.9 \%$ of theoretical density (TD).

\subsection{Sintering experiments}

The conventionally heated samples were sintered in air using a dilatometer (Setsys 16/18, SETARAM, France). In the case of microwave sintering, experiments were performed on a special microwave heating system designed and described by Żymełka et al. ${ }^{18}$. This heating system was equipped with a fixed frequency of $2.45 \mathrm{GHz}$ microwave generator (GMP30K, SAIREM, France) with continuous adjustable output power $\sim 3 \mathrm{~kW}$, along with a multimode cavity of dimension of $430 \mathrm{~mm} \times 430 \mathrm{~mm} \times 490 \mathrm{~mm}$. Because of the low dielectric loss factor $(\tan \delta)$ of alumina at room temperature, a SiC ring was used as susceptor to initially hybrid heat samples through efficient coupling at low temperature. Two infrared pyrometers have been used to measure the temperature of the sample, as mentioned in the previous section. In order to obtain the continuous shrinkage curves, a CCD camera (SLC2050MTLGEC, 14-bit, $1600 \times 1200$, SVS-VISTEK, Germany) records the changes in the radius of the sample during its whole heating cycle. The configuration of this microwave sintering and measuring system was previously reported by Zuo et al. ${ }^{15}$ This contactless system allows to precisely control the thermal cycles while in situ measuring the shrinkage during the overall microwave sintering process. This as-described process can be conducted without either interference with the electromagnetic field or stress subjected on the samples. That is meaningful for the analysis of the microwave sintering process. In addition, it makes the rigorous comparison with conventional sintering to be possible.

The studies in terms of thermodynamics were carried out in non-isothermal conditions. Herein, conventional sintering experiments were performed at heating rates of $1.6,4,10$ and $25^{\circ} \mathrm{C} / \mathrm{min}$, whereas the heating rates of $10,25,50$ and $100{ }^{\circ} \mathrm{C} / \mathrm{min}$ were used for microwave sintering. Collectively, the temperature of sample was raised to $1550^{\circ} \mathrm{C}$ and held at this temperature for $5 \mathrm{~min}$ for both heating methods. Based on the non-isothermal heating treatment, first, the apparent activation

Table 1

Sintering processing parameters for each set of alumina.

\begin{tabular}{|c|c|c|c|c|c|}
\hline $\mathrm{Al}_{2} \mathrm{O}_{3}$ powders & $\mathrm{MgO}$ (wt. ppm) & $S_{\text {BET }}\left(\mathrm{m}^{2} / \mathrm{g}\right)$ & $\Delta T_{\max }\left({ }^{\circ} \mathrm{C}\right)$ & \multicolumn{2}{|c|}{ Apparent activation energy $Q(\mathrm{~kJ} / \mathrm{mol})$} \\
\hline \multirow[t]{2}{*}{ A6 } & 0 & 6 & 34 & $\mathrm{CS}$ & $652 \pm 45$ \\
\hline & & & & MW & $451 \pm 77$ \\
\hline \multirow[t]{2}{*}{ A6-500 } & 500 & 6 & 47 & $\mathrm{CS}$ & $596 \pm 13$ \\
\hline & & & & MW & $478 \pm 51$ \\
\hline \multirow[t]{2}{*}{ A6-4000 } & 4000 & 6 & 50 & $\mathrm{CS}$ & $586 \pm 5$ \\
\hline & & & & MW & $500 \pm 30$ \\
\hline \multirow[t]{2}{*}{$\mathrm{A} 19^{20}$} & 0 & 19 & 46 & $\mathrm{CS}$ & $528 \pm 22$ \\
\hline & & & & MW & $440 \pm 8$ \\
\hline
\end{tabular}


(a) Conventional sintering

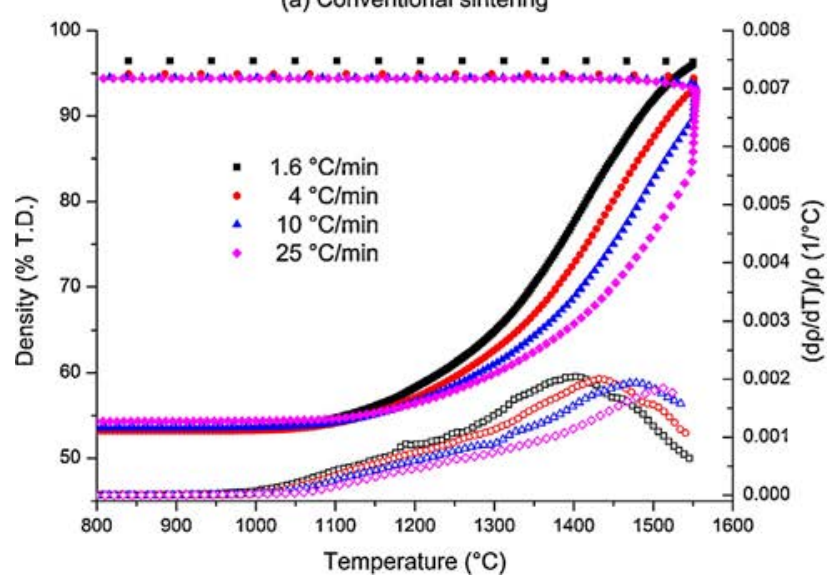

(b) Microwave sintering

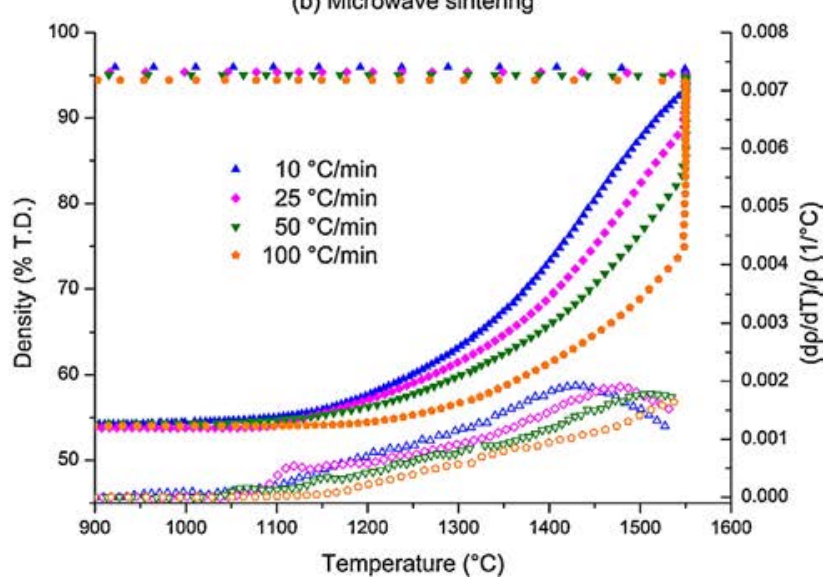

Fig. 2. Density and densification rate versus temperature during conventional and microwave sintering of samples A6, at different constant heating rates.

energy of conventional and microwave sintering can be found out, respectively. Furthermore, the exactly identical temperature/time profile (at 10 and $25^{\circ} \mathrm{C} / \mathrm{min}$ ) can give direct access to the comparison between microwave and conventional heating processes.

To study the densification kinetics, each set of samples was isothermally sintered at temperatures from 1200 to $1450{ }^{\circ} \mathrm{C}$ under microwave and conventional sintering, with a heating rate of 100 and $25^{\circ} \mathrm{C} / \mathrm{min}$, respectively, and with different dwell durations. This part of investigation was based on another section of study with respect to the interrelationship between grain size and relative density of a sample, which is the sintering trajectory. In order to record the microstructure evolution during the entire densification stage, we have sintered in a conventional and microwave furnaces, respectively, sufficient number of samples using different thermal cycles.

After the sintering process, densities and densification rate were computed from the final densities measured by Archimedes' method with absolute alcohol as the immersion media and from the recorded shrinkage data. The final density was averaged from at least three measurements, and the measurement deviations were less than $0.23 \%$.

\subsection{Microstructural characterization}

The microstructures of sintered alumina samples were observed by Scanning Electron Microscopy (SUPRA 55, Carl Zeiss, Germany) on gold coated fractured surfaces or polished and thermally etched cross-sections, according to the sintering temperature and the final density. Thermal etching was done at temperatures approximately 70 to $120^{\circ} \mathrm{C}$ below the sintering temperature in a vertical conventional tube furnace (Pyrox, France). Alumina sample was initially placed on the bottom of the furnace, and was raised to the central part when the temperature of furnace reached to the set value. After holding $5 \mathrm{~min}$ at the etching temperature, sample was dropped to the bottom of furnace again. The mean grain size for each sample was evaluated by the linear intercept method on more than 300 grains. A statistical correction factor of 1.56 was applied to the measured apparent grain size. ${ }^{19}$
Additionally, a selected set of samples (A6-4000) was observed by transmission electron microscopy (Tecnai F30, FEI, USA) at $300 \mathrm{kV}$ to check the presence of second phase $\left(\mathrm{MgAl}_{2} \mathrm{O}_{4}\right.$ spinel) precipitate at grain boundaries. Focused ion beam (NVision 40, Carl Zeiss, Germany) tool has been applied for the preparation of the specimens that have been observed with TEM.

\section{Results and discussion}

\subsection{Comparison of densification behaviors between conventional and microwave sintering}

Investigation of the influence of powder natures on microwave beneficial effect should be based on a comparative study between conventional and microwave sintering processes with identical thermal cycle. The heating rate of $25^{\circ} \mathrm{C} / \mathrm{min}$ is common for these two heating techniques. According to Fig. 2, a quantitative assessment of the microwave effect on densification behaviors has been performed at $25^{\circ} \mathrm{C} / \mathrm{min}$ by using $\Delta \rho$ and $\Delta T_{\max }$ as criterions. $\Delta \rho$ is the density difference between microwave and conventionally sintered samples for a given temperature, which is obtained from the density curves. $\Delta T_{\max }$ is the gap between the temperatures for which the maximum densification rate is, respectively, observed under conventional and microwave sintering, labeled as $\Delta T_{\max }=\left(T_{\max }\right)_{\mathrm{CS}}-\left(T_{\max }\right)_{\mathrm{MW}}$. This criterion is obtained from the densification rate curves. It is reasonably assumed that a higher $\Delta \rho$ and a higher $\Delta T_{\max }$ correspond to an enhanced microwave effect on densification. The variation of $\Delta \rho$ (Density MW $_{-}$Density $\left._{\mathrm{CS}}\right)$ as a function of Density $_{\mathrm{CS}}$ has been drawn and shown in Fig. 3, while the $\Delta T_{\max }$ values for each sample are presented in Table 1.

According to Fig. 3, for undoped $6 \mathrm{~m}^{2} / \mathrm{g}$ alumina, the maximum of $\Delta \rho$ exceeds $4 \%$ at $78 \%$ of TD. In the presence of $\mathrm{MgO}$ dopant, however, it rises up to about $8 \%$. Similarly, an increase of specific surface area from 6 to $19 \mathrm{~m}^{2} / \mathrm{g}$ also causes the $\Delta \rho$ peak value to vary from $4 \%$ to $8 \%$. Otherwise, the $\Delta T_{\max }$ values depicted in Table 1 are in good agreement with the results obtained in terms of $\Delta \rho . \Delta T_{\max }$ appears to be higher for magnesia doped sample or for undoped samples with higher specific 


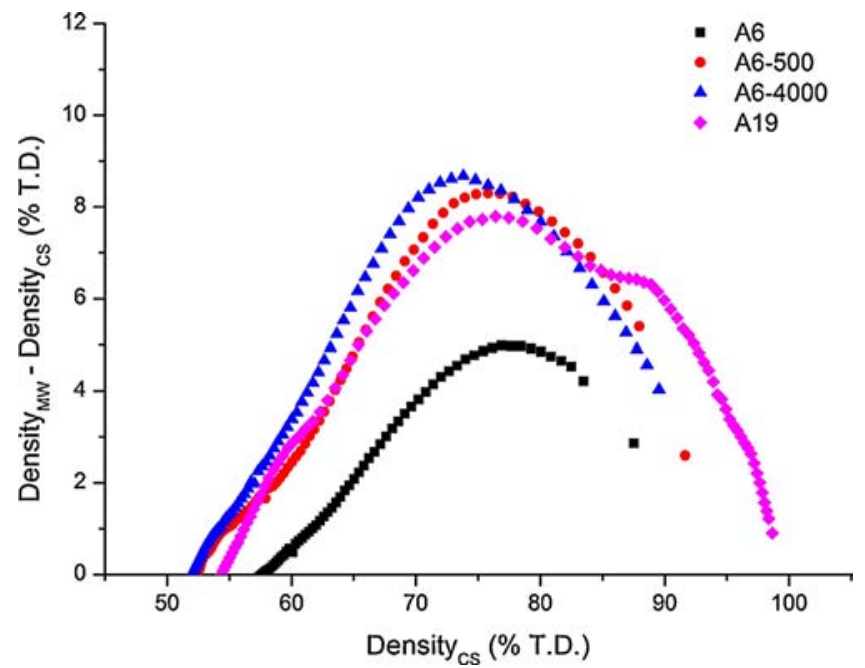

Fig. 3. Mean density difference variations between microwave (MW) and conventionally (CS) on heated $\mathrm{Al}_{2} \mathrm{O}_{3}$ samples plotted against conventionally sintered density: $6 \mathrm{~m}^{2} / \mathrm{g} \mathrm{Al}_{2} \mathrm{O}_{3}$ powder with different $\mathrm{MgO}$ doping amounts $(0$, 500, and $4000 \mathrm{wt} / \mathrm{ppm}$ ); and undoped $\mathrm{Al}_{2} \mathrm{O}_{3}$ powder with different specific surface areas $\left(6\right.$ and $\left.19 \mathrm{~m}^{2} / \mathrm{g}\right)$.

surface area. As a result, it can be stated that either the existence of $\mathrm{MgO}$ dopant or a decrease of particle size is beneficial to improve the microwave effect on the densification process of alumina. Furthermore, investigation on sintering thermodynamics and densification kinetics should be focused on the intermediate stage of sintering, where microwave can bring about a noticeable densification enhancement (Fig. 3).

\subsection{Sintering trajectory and analysis of the microstructure}

With the purpose of discussing the sintering trajectory, several factors should be fully considered, such as the initial density, thermal cycle, doping type and level, particle size, sintering stage, and the heating technique used. However, the works reported in the literature always lacked a detailed and clear fundamental study of the microstructural development during microwave sintering of alumina. For example, Xie et al. ${ }^{21}$ reported a grain growth trajectory with densification which follows a single path for conventional and microwave sintering methods. Nevertheless, they neglected the possible effect of $0.05 \mathrm{wt} \%$ of sintering aids. In a recent study of Zuo et al. ${ }^{22}$, the comparison was done in taking account the effect of thermal cycle. However, in this latter, the sintering trajectory in the final stage has not been determined. In the present work, all the recorded sintering trajectories were based on the identical initial density at different thermal cycles. Moreover, these trajectories were plotted for the entire densification stage. As a consequence, a net comparison of the effect of $\mathrm{MgO}$ doping level and particle size on grain growth could be clearly examined.

Fig. 4 displays the evolution of grain size versus relative density of each alumina samples with conventional and microwave heating processes. If we take an intra-comparison for each alumina, it is interesting to note that the grain growth follows a single path for a given heating method. Its variation only depends on the density, but not on the thermal cycles. In this sense, the use of rapid heating rate cannot be responsible for the improvements in microstructure, at least within this tested range (from 1.6 to $\left.100{ }^{\circ} \mathrm{C} / \mathrm{min}\right)$. In terms of the inter-comparison among different alumina, these sintering trajectories have shown a noteworthy point as well: for the $\mathrm{A} 6 \mathrm{Al}_{2} \mathrm{O}_{3}$, a relatively evident gap exist between grain-growth trajectories under conventional and microwave sintering, whereas no remarkable difference was detected for each of the other three powders. As an example to demonstrate this difference in grain size, the microstructures of conventionally sintered and microwave sintered A6 samples, of relative densities around $87 \%$ and $95 \%$, are shown in Fig. 5. This indicates that the microwave fields tend to retard the grain growth for the A6 samples. So the question raised by that is why is grain growth retardation only observable on an undoped alumina, having a relatively higher particle size, but not in $\mathrm{MgO}$-doped or fine-grained undoped samples?

In one study of Golestani-fard et al. ${ }^{13}$, a different microstructural evolution of microwave-sintered pure alumina as compared to that under conventional heating was also reported. However, in their study, this important phenomenon was just roughly attributed to a shorter sintering time and a lower sintering temperature. Obviously, it is not the suitable explanation for the present results on account of single grain-growth paths for the three alumina except A6. Therefore, to clearly state about this issue, the discussion should take into account the influence of $\mathrm{MgO}$ and particle size on grain growth.

As far as we know, $\mathrm{MgO}$ is usually used as a sintering additive in alumina and it is a grain growth inhibitor. This effect can be clearly seen in Fig. 4(b) and (c) as compared to (a) for both conventional and microwave processes. For A6-500 alumina samples, accordingly the phase diagram previously reported, ${ }^{15}$ the magnesium atoms are expected to be in solid-solution into the alumina lattice and extra added magnesia should segregate at surfaces and interfaces (grain boundaries region). In this domain, solid-solution formation and segregation mechanisms are considered to be the dominant mechanisms controlling the grain-growth inhibition. ${ }^{23,24}$ For A6-4000 samples, an excessive $\mathrm{MgO}$ doped in $\mathrm{Al}_{2} \mathrm{O}_{3}$ should lead to a formation of precipitates $\left(\mathrm{MgAl}_{2} \mathrm{O}_{4}\right.$ spinel $)$ at grain boundaries. In order to check the presence of spinel phase, a conventionally sintered sample (97.39\% of TD, grain size of $1102 \pm 81 \mathrm{~nm}$ ) and a microwavesintered sample $(98.92 \%$ of TD, grain size of $1336 \pm 94 \mathrm{~nm})$, having the A6-4000 composition were observed using TEM (both samples were sintered using the same thermal cycle: $25^{\circ} \mathrm{C} / \mathrm{min}$ to $1550{ }^{\circ} \mathrm{C}$, with a dwell duration of $5 \mathrm{~min}$ ). During observations, the composition and crystallographic structure were, respectively, determined by energy-dispersive X-ray spectroscopy (EDS) analysis and electron diffraction. It has been observed precipitates located in grain boundaries region. Brightfield image of such precipitate with the corresponding EDS spectrum and electron diffraction pattern are shown in Fig. 6. These precipitates were observed indifferently on microwave sintered or conventional sintered samples. This shows that the pseudo-equilibrium phase diagram $\left(\mathrm{Al}_{2} \mathrm{O}_{3}-\mathrm{MgO}\right.$ system $)$ given in reference, ${ }^{15}$ accounts well for materials sintered in both microwave and conventional heating. No difference has been observed on both sintered samples at nano-scale through TEM 

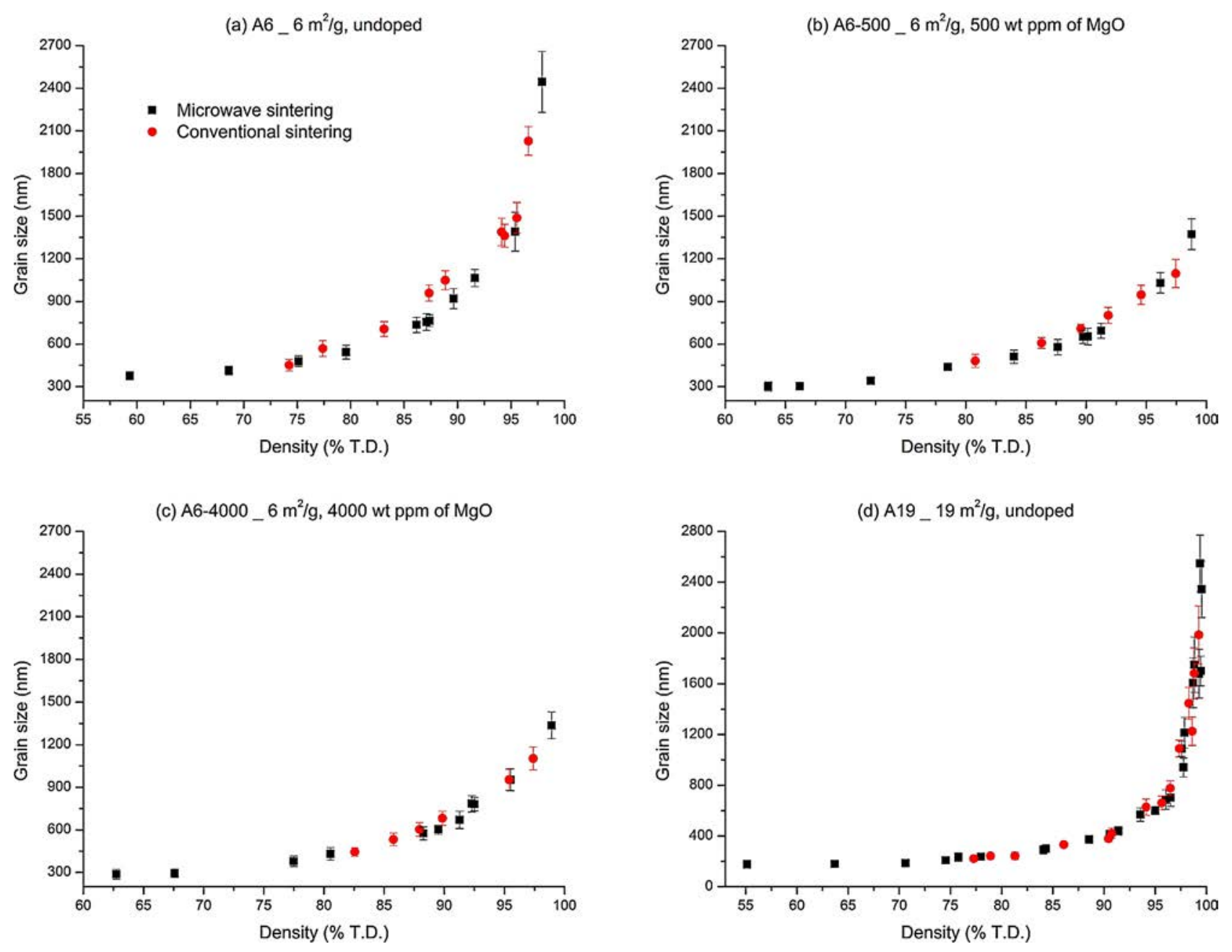

Fig. 4. Variations of grain size $(G)$ with relative density $(\rho)$ of conventionally sintered and microwave-sintered samples by using different thermal cycles.
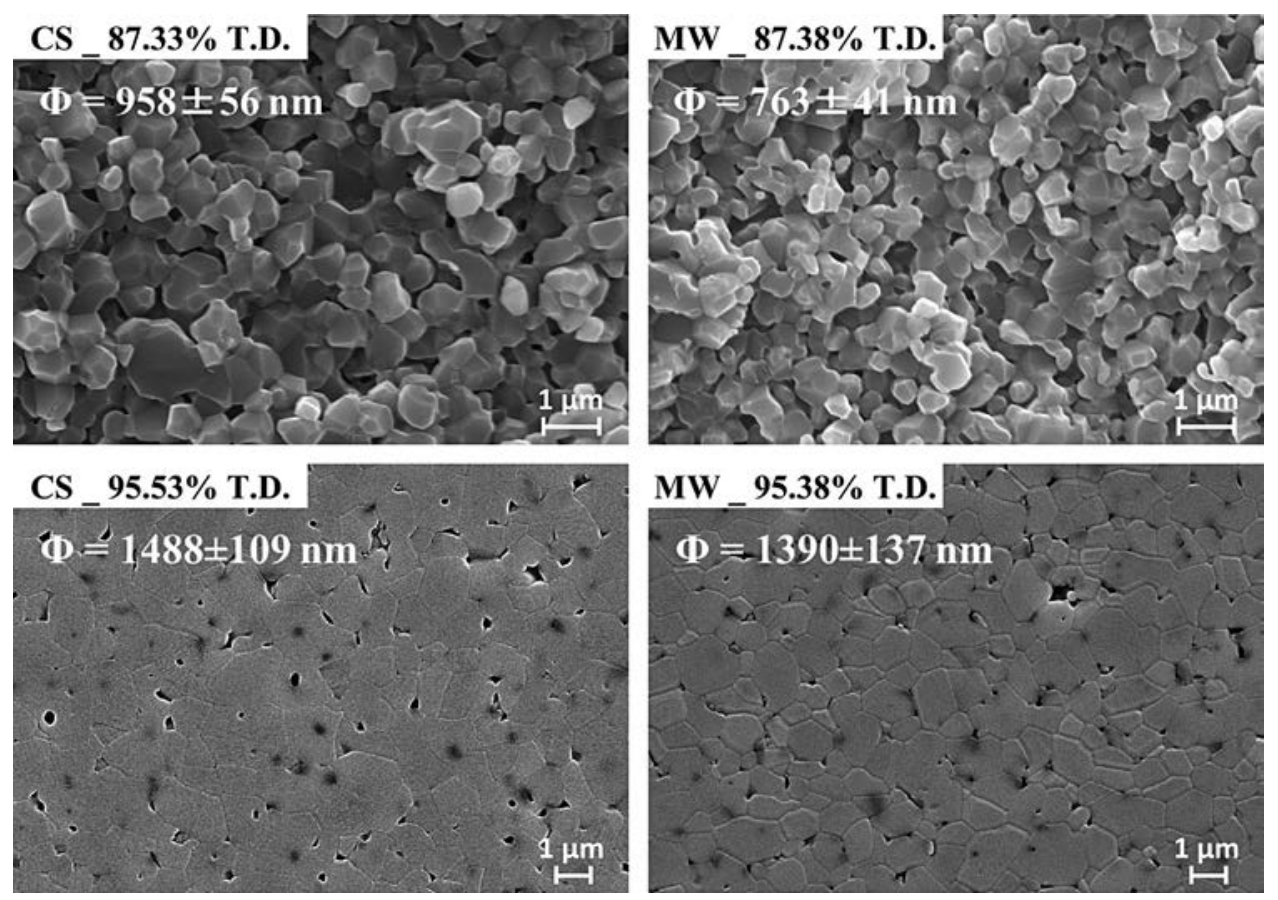

Fig. 5. SEM micrographs of conventionally sintered (CS) and microwave-sintered (MW) A6 samples, of relative density around $87 \%$ and $95 \%$. 

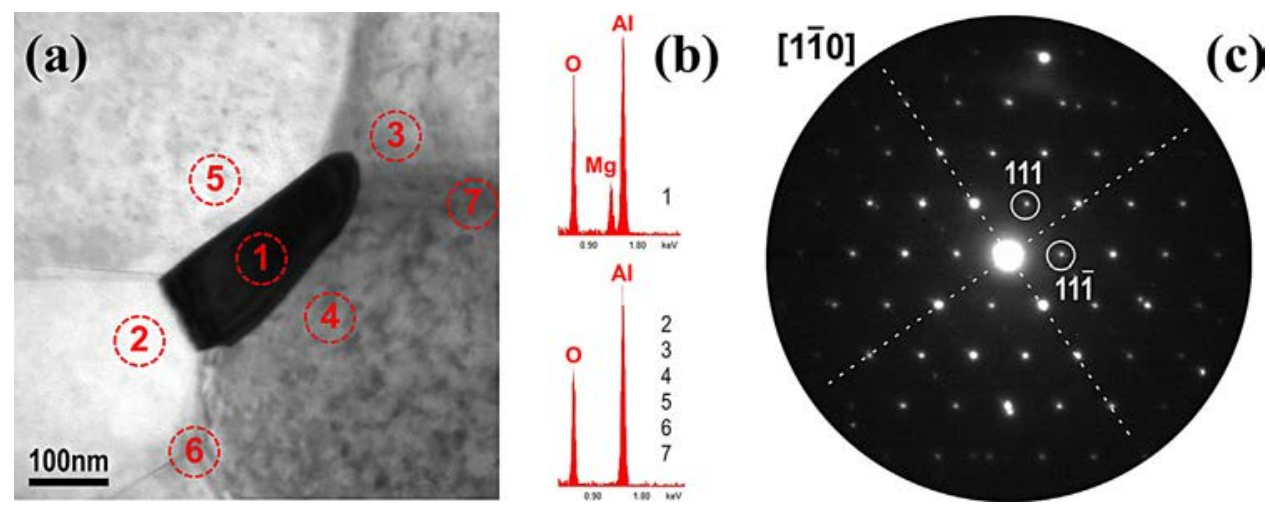

Fig. 6. $\mathrm{MgAl}_{2} \mathrm{O}_{4}$ spinel precipitate: (a) TEM bright field image, (b) corresponding EDS spectrum, and (c) corresponding electron diffraction pattern.

investigation. It is then well understood that $\mathrm{MgAl}_{2} \mathrm{O}_{4}$ spinel precipitates, located at grain junctions, limit the grain-growth through the Zener effect. ${ }^{24}$ As no nano-scale microstructural difference has been observed on samples sintered through both techniques, no difference of sintering trajectories has been observed. With regard to the A19 alumina, its particle size is small enough (about $100 \mathrm{~nm}$ ), corresponding to a more extensive and more uniform pore distribution which could also restrain grain-boundary movement. ${ }^{25}$

To summarize, when taking into account the presented results, it is believed that the electromagnetic field has a positive effect to limit grain growth on alumina during sintering. However, as for $\mathrm{MgO}$ doped or nano-sized samples, other parameters may play a major role in alumina grain-growth (Zener effect). This is the reason why, for the alumina powders selected in this study, the effect of microwave on the grain growth is only observable for undoped and relatively coarse grained alumina.

\subsection{Evaluation of the apparent activation energy of densification from constant heating rate (CHR) approach}

The densification rate is correlated to apparent activation energy $Q$ by the following equation:

$\frac{\mathrm{d} \rho}{\mathrm{d} t}=A \frac{e^{-Q / R T}}{T} \frac{f(\rho)}{G^{n}}$

where $A$ is a material parameter independent of temperature $T, R$ the gas constant, $f(\rho)$ a function of density, $G$ the grain size and $n$ the grain size exponent dependent on the dominant diffusion mechanism. Rearranging and taking the logarithm of both sides of Eq. (1), one obtains:

$\ln \left(T \frac{\mathrm{d} \rho}{\mathrm{d} T} \frac{\mathrm{d} T}{\mathrm{~d} t}\right)=-\frac{Q}{R T}+\ln [f(\rho)]+\ln A-n \ln G$

Assuming that the grain size depends only on the density, $Q$ can be estimated for a given density interval from plots of the left-hand side of Eq. (2) vs. 1/T, by measuring the densification rate from the CHR sintering experiments. ${ }^{26}$ The CHR approach has been used over a relative density range of $60-85 \%$ of TD for each set of $\mathrm{Al}_{2} \mathrm{O}_{3}$, as shown in Fig. 7.

According to whatever set of alumina in Fig. 7, for each density, the four points obtained at four heating rates are well aligned. The $Q$ value for densification for each density could be determined from the slope of the linear fit. On the one hand, whatever the heating method used, the slopes (fitting lines) at different densities are approximately parallel. It indicates that over the density range investigated, the sintering is activated by unique apparent activation energy. This means that a similar dominant diffusion mechanism(s) occurs over the investigated density range. On the other hand, it is noted that, for a given density, the lines for microwave sintering shift towards lower temperature direction, relative to those for conventional sintering. This is due to the enhanced solid-state diffusion induced by the electromagnetic field and consistent with the microwave-enhanced densification demonstrated in Fig. 3.

The apparent activation energy values determined through CHR method are shown in Table 1. First of all, these typical values (from 450 to $650 \mathrm{~kJ} / \mathrm{mol}$ ) correspond to the value usually obtained for grain-boundary diffusion controlled mechanism in alumina. ${ }^{7,9}$ Second, as highlighted in comparison for each set of $\mathrm{Al}_{2} \mathrm{O}_{3}$, the average apparent activation energy values are significantly lowered when microwave is applied. For A6-500, A6-4000 and A19 alumina, these reductions are about $100 \mathrm{~kJ} / \mathrm{mol}$. In Fig. 4, all the three samples show a single grain growth path independent of thermal sources or cycles, respectively. From thermodynamics viewpoint, an identical grain size evolution with density corresponds to an identical intrinsic driving force for conventionally and microwave-sintered samples throughout the densification process. Consequently, the reduction of activation energy during microwave sintering should benefit from an external driving force for densification. With regard to A6 alumina, the gap of average apparent activation energy values between two heating techniques rises to $200 \mathrm{~kJ} / \mathrm{mol}$. This could be rationalized by the combined effect of both the additional driving force for densification as mentioned above and the inhibited grain growth provided by the microwave electromagnetic field.

\subsection{Densification kinetics analysis based on isothermal sintering}

In order to study in more detailed manner the mechanism(s) involved during the densification of alumina through 
(a) A6_ $6 \mathrm{~m}^{2} / \mathrm{g}$, undoped

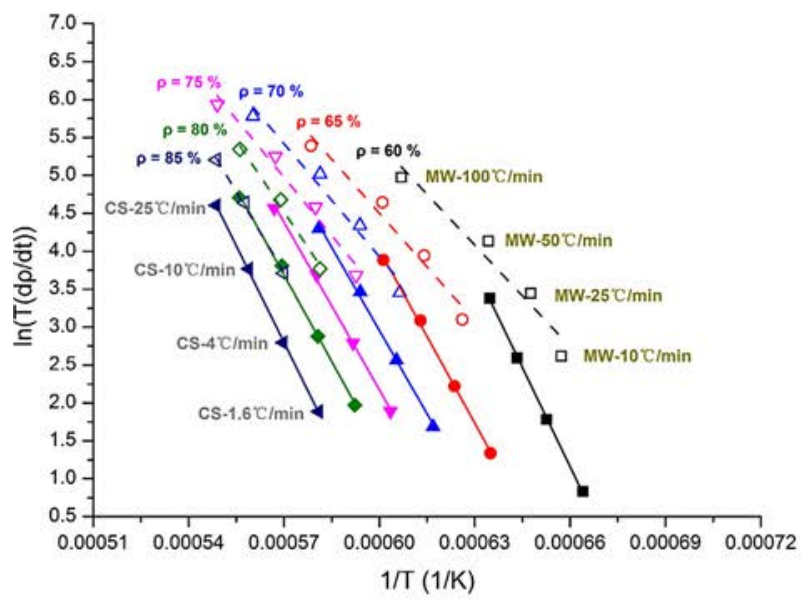

(c) $\mathrm{A} 6-4000 \_6 \mathrm{~m}^{2} / \mathrm{g}, 4000$ wt ppm of $\mathrm{MgO}$

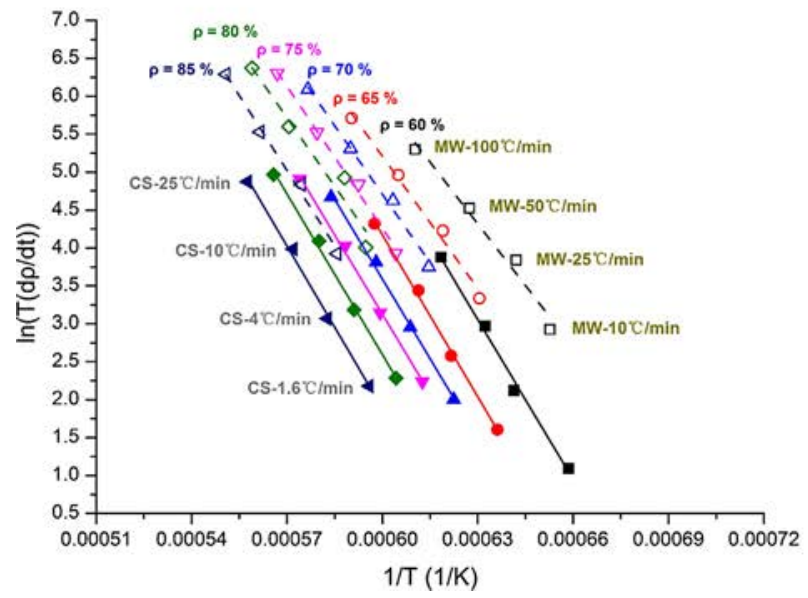

(b) A6-500_6 $\mathrm{m}^{2} / \mathrm{g}, 500 \mathrm{wt} \mathrm{ppm}$ of $\mathrm{MgO}$

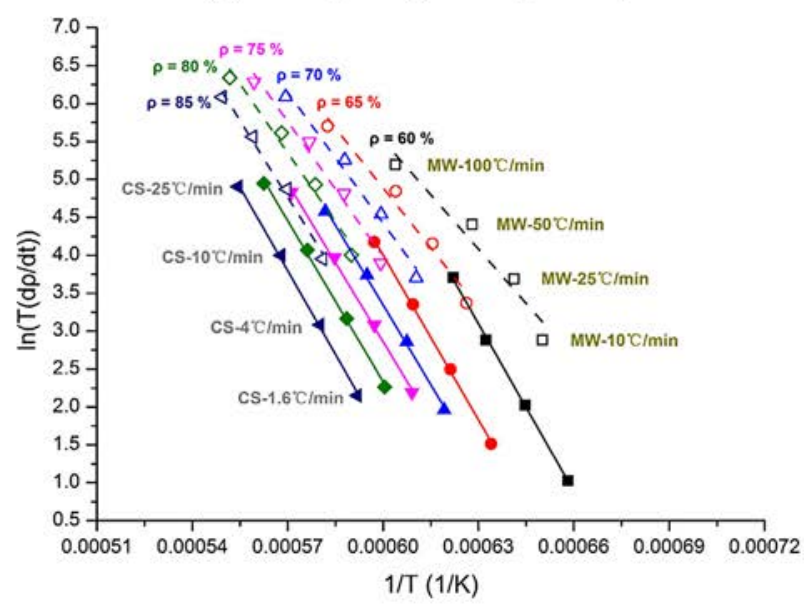

(d) $\mathrm{A} 19 \_19 \mathrm{~m}^{2} / \mathrm{g}$, undoped [20]

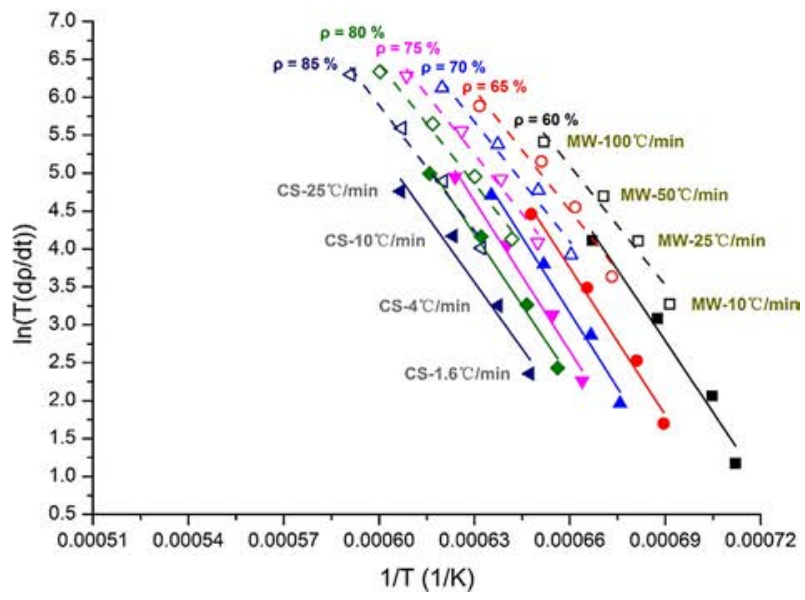

Fig. 7. Arrhenius-type plots of densification data to estimate the apparent activation energy using different constant heating rates at given relative densities, under conventional (CS) and microwave (MW) sintering of each set of $\mathrm{Al}_{2} \mathrm{O}_{3}$.

microwave sintering, further analysis of densification kinetics was done in using Coble's geometrical model of intermediate stage sintering. ${ }^{27}$ According to this model, the relative densification rate of isothermal sintering can be described by ${ }^{24}$ :

$\frac{\mathrm{d} \rho}{\rho \times \mathrm{d} t} \propto \frac{D_{l} \gamma_{s} V_{m}}{R T G^{3}} \quad$ (Densification by lattice diffusion)

$\frac{\mathrm{d} \rho}{\rho \times \mathrm{d} t} \propto \frac{D_{b} \delta_{b} \gamma_{s} V_{m}}{R T G^{4}}$

(Densification by grain-boundary diffusion)

where in $D_{l}$ is the lattice diffusion coefficient, $\gamma_{s}$ the specific surface energy of the solid, $V_{m}$ the molar volume of the solid, $R$ the gas constant, $T$ the absolute temperature, $G$ the grain size, $D_{\mathrm{b}}$ the grain-boundary diffusion coefficient, and $\delta_{b}$ the diffusion thickness of grain-boundary diffusion. From Eqs. (3) and (4), the determination of the dominant diffusion mechanism controlling the densification is to determine the value of exponent for $G$, labeled as $n$. The densification behavior and kinetics parameter $n$ of different alumina samples were given in Fig. 8.
As shown by the densification curves in Fig. 8 (on the left), at the same isothermal sintering temperature, a shorter treatment time is needed to achieve the same density when microwave heating is used. In terms of the kinetics parameter $n$, all these values determined in Fig. 8(a)-(c) are closed to the value of 4 . At this point, it suggests that the grainboundary diffusion predominantly controls the densification of $6 \mathrm{~m}^{2} / \mathrm{g}$ alumina powders during the intermediate stage of both conventional and microwave sintering. This result is consistent with that obtained in terms of thermodynamics (apparent sintering activation energy). Nevertheless, when the specific surface area is $19 \mathrm{~m}^{2} / \mathrm{g}$, the values of $n$ significantly decrease for both heating methods (Fig. 8(d)). The particle size appears to affect significantly of the $n$ value. In view of the $n$ values during microwave sintering of A19 alumina $(\approx 3)$, that value suggests that densification could be governed by one of the three possible mechanisms: lattice diffusion in free sintering; grain-boundary diffusion in pressure-assisted sintering; or inseries "interface-reaction/grain-boundary diffusion". The first assumption conflicts with the consensus that the dominant path for diffusion in the intermediate stage of alumina sintering is 
(a) $\mathrm{A6} \_6 \mathrm{~m}^{2} / \mathrm{g}$, undoped
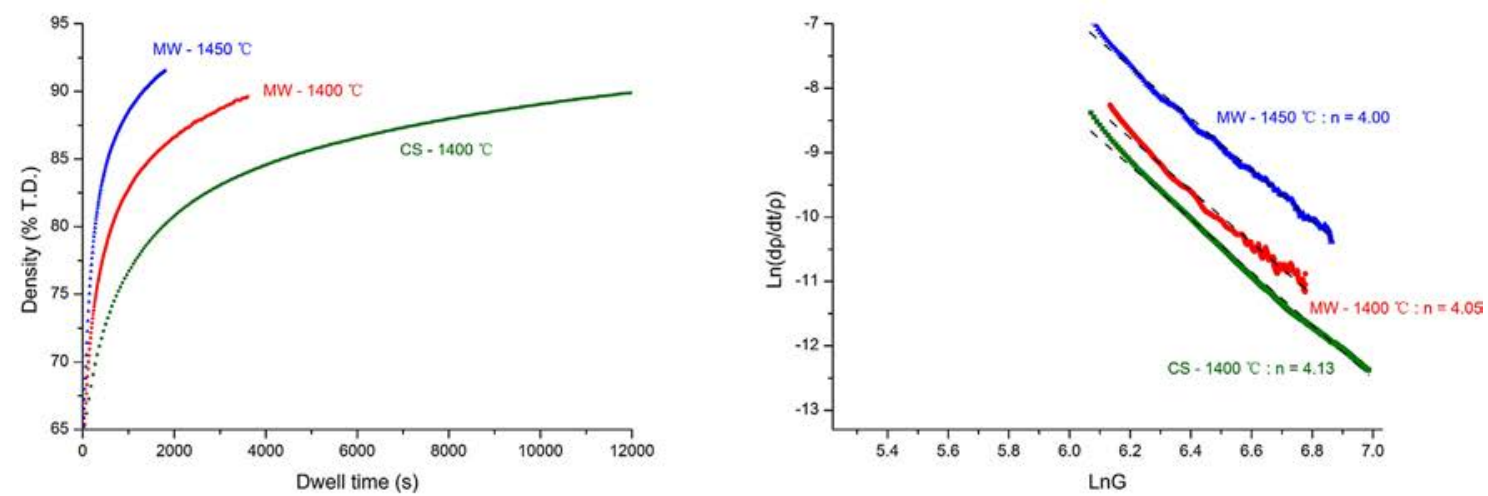

(b) $\mathrm{A6-500} \_6 \mathrm{~m}^{2} / \mathrm{g}, 500 \mathrm{wt} \mathrm{ppm}$ of $\mathrm{MgO}$
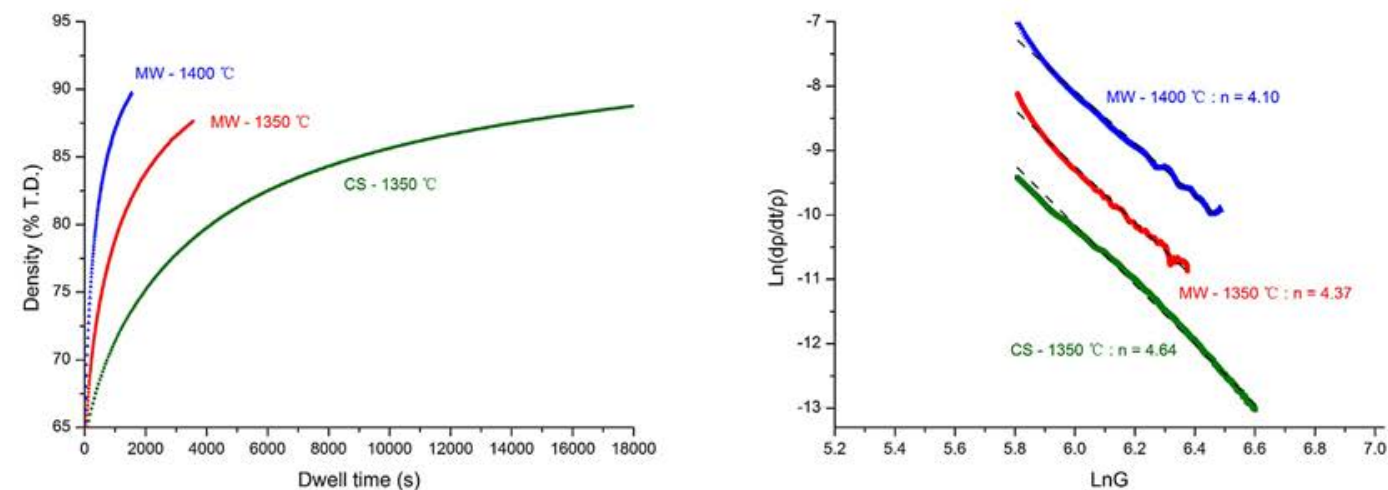

(c) $\mathrm{A6}-4000$ _ $6 \mathrm{~m}^{2} / \mathrm{g}, 4000 \mathrm{wt} \mathrm{ppm}$ of $\mathrm{MgO}$
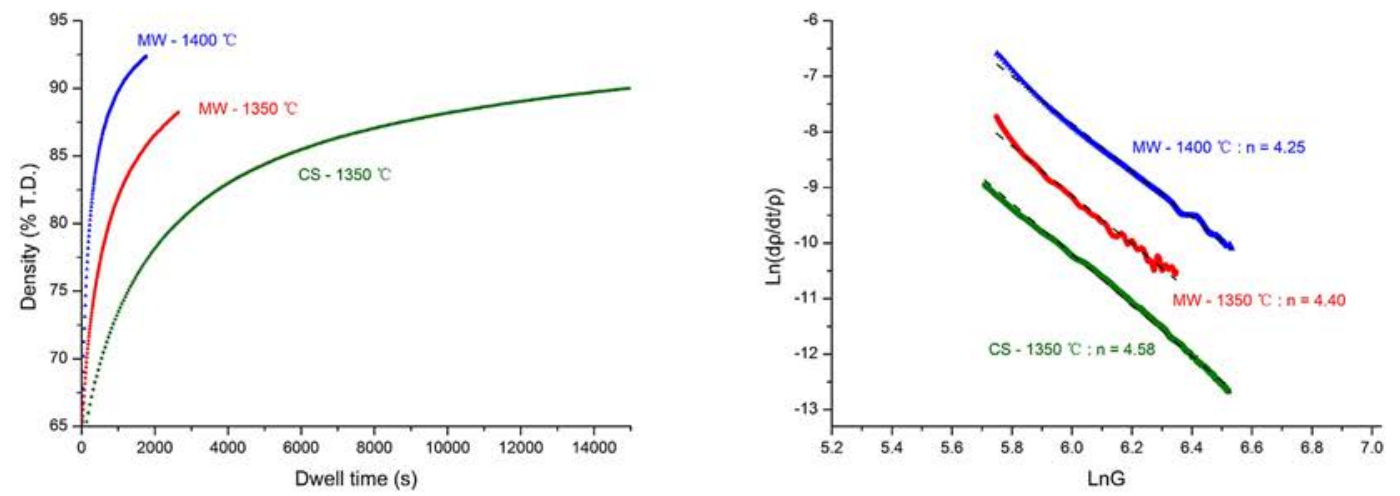

(d) $\mathrm{A19} \_19 \mathrm{~m}^{2} / \mathrm{g}$, undoped [22]
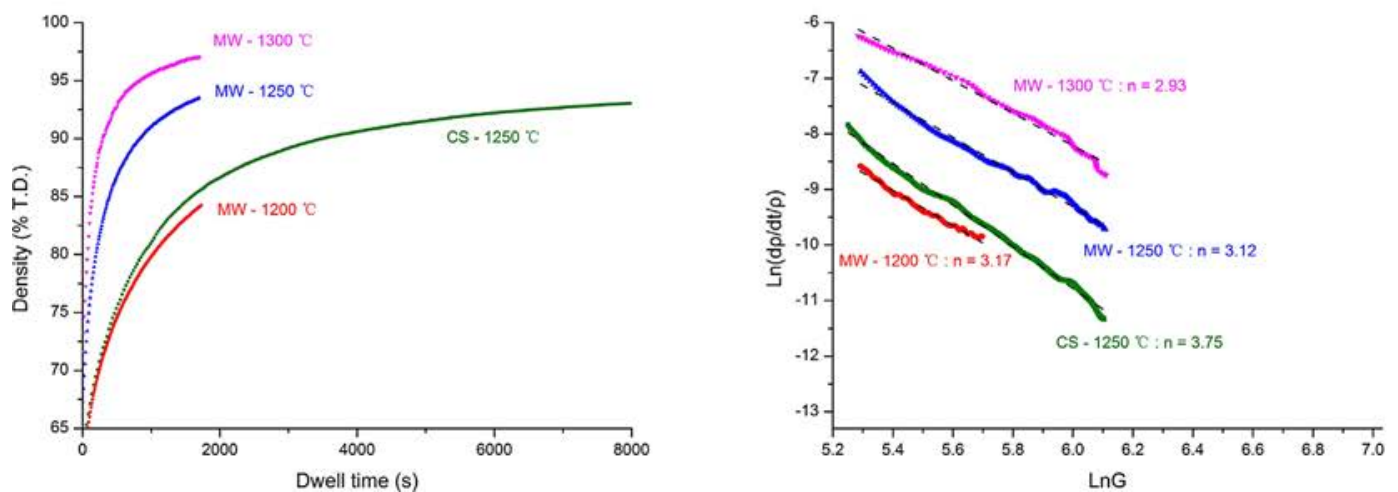

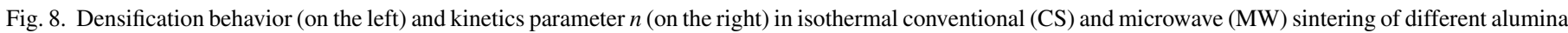
at different dwell temperatures. Values of $n$ are the slopes of the different dotted fitting lines. 
along the grain boundary. The two others assumptions will be discussed later.

\subsection{Discussion and hypotheses on the involved mechanism(s) in densification and grain growth during microwave sintering}

Direct comparison of densification behavior under identical experimental conditions between conventional and microwave sintering of alumina has shown that application of a microwave field to a powder compact results in a remarkable decrease in the sintering temperature as well as the sintering time. This is in good agreement with the lower apparent activation energy values determined during the intermediate stage of microwave sintering. This difference in activation energy values indicates that the solid-state diffusion process for densification can be enhanced under electromagnetic field. At this point, the question is what would be the main reason for such enhancements in the diffusion process: would it be a field-assisted diffusion related to ponderomotive effect ${ }^{5}$ and/or thermal diffusion due to local Joule effect? ${ }^{6}$

As reported in the literature, the local Joule heating at grain boundaries which may occur during microwave sintering has often been seen as a mechanism responsible for grain growth inhibitor. ${ }^{6,28}$ If this assumption is valid, the driving force for grain growth should be reduced in all cases during microwave sintering. However, as previously seen in Fig. 4, there is no noticeable difference in the grain growth trajectory for A6-500, A6-4000 and A19 samples sintered by different thermal sources. Furthermore, if the grain growth retardation is affected by a local over-heating on account of applied electric field, the action effect should be changed as the magnitude of field changes. Nevertheless, grain growth during microwave sintering always follows a single path, independently of the heating rate (this latter being correlated with the electromagnetic field magnitude). In addition, the thermal conduction efficiently equilibrates the temperature at microscale, and it is questionable that the temperature difference between the grain boundary and the grain interior could be significant. ${ }^{29}$

In terms of the microwave influence on mass transport in densification, we can also find the relative imperfection of the aspect of local Joule heating. At first, the direct current electric field is different from the electromagnetic field, and hence the results about the effect of direct current electric field on diffusion phenomena may be not directly applicable to microwave processing. Second, as mentioned above, a slight thermal gradient between the grain boundary and the bulk will be difficult to enhance the thermal diffusion. Otherwise, several experimental studies also indicate a non-thermal microwave effect on transport phenomena. ${ }^{4,30}$ As a consequence, by taking the viewpoints of grain growth and densification, a non-thermal effect of microwave electromagnetic field on densification mechanism(s) should be more likely.

As discussed above, the electromagnetic field, $\mathrm{MgO}$ dopant and porosity are parameters that all could act as grain growth inhibitor. It means that the grain growth retardation can display due to microwave field, however, this effect can also be more or less hidden by some other parallel factors, e.g. the second phase precipitates and the fine pores at grain boundaries. According to Panichkina et al. ${ }^{31}$, the fine porosity persists for a long periods of time during microwave sintering. This is consistent with microstructures shown in Fig. 5, the microwave-sintered sample at relative density about $95 \%$ has the finer residual pores relative to that conventionally heated. The residual fine pores at grain boundaries allow inhibiting grain growth due to the pinning effect. In other words, the microwave effect on microstructural evolution could be indirect.

With regard to densification kinetics, the value of parameter $n$ is very sensitive to the particle size of powder compacts. As shown in Fig. 8, a decrease of powder specific surface area from 19 to $6 \mathrm{~m}^{2} / \mathrm{g}$ leads to an increase of the $n$ value from 3 to 4 under microwave sintering. On the one hand, assuming that the enhanced vacancy motion caused by a highfrequency microwave field in the interface regions can induce an electromagnetic pressure to the crystal,,$^{3,22,32}$ this induced electromagnetic force should weaken as the grain size is large. If we assume that the electromagnetic pressure is mostly applied on the grain boundary region, it is expected an enhanced effect on material having small grain size. In this way, the similar pressure-assisted grain-boundary diffusion $(n=3)$ is no more remarkable. Meanwhile, on the other hand, one must also note the slight increase of $n$ value during conventional heating, as the specific surface area decreased. Note that the particle size of A19 alumina powders $\left(19 \mathrm{~m}^{2} / \mathrm{g}\right)$ is fine enough, about $100 \mathrm{~nm}$. If the process of interface-reaction is taken into account, this variation of kinetics parameter $n$ may be simply because of the accelerated grain-boundary diffusion by microwave when the powders are finer. Grain-boundary diffusion and interfacereaction are two sequential processes in diffusion. ${ }^{25}$ Their total apparent densification rate $R_{\text {Total }}$ can be expressed in the form:

$$
\frac{1}{R_{\text {Total }}}=\frac{1}{R_{G B}}+\frac{1}{R_{I R}}
$$

where $R_{G B}$ is the rate of grain-boundary diffusion, and $R_{I R}$ the rate of interface-reaction. Therefore, the slower mechanism will dominate the densification process. In the present work, the A19 alumina has a smaller particle size compared with the others, indicating more important grain-boundary regions. These structural non-uniformities are benefit on the ponderomotive effects, and hence the diffusion of vacancies/charged particles along grain boundary is accelerated under the action of electromagnetic field. As the grain-boundary diffusion is faster, interface-reaction gradually becomes the dominant mechanism for densification. In the literature, there has not yet been any experimental result showing the value of $n$ in the case of densification mechanism by interface-reaction. However, in the process of creep, $n$ is equal to 1 when interface-reaction is the dominant mechanism. ${ }^{33}$ Correspondingly, the $n$ values are 2 and 3 when the creep rates are lattice diffusion controlled and grainboundary diffusion controlled, respectively. Note that in the process of sintering, for the lattice diffusion and grain-boundary diffusion, $n$ values become 3 and 4, respectively. Therefore, we can infer that, when interface-reaction becomes the dominant sintering mechanism, $n$ value should be no more than 2 . In this 
sense, it can be proposed that a value of kinetics parameter $n$ equal to 3 corresponds to a densification in-series "interfacereaction $(n \leq 2)$ /grain-boundary diffusion $(n=4)$ " mechanism controlling the microwave sintering of fine alumina powders. In any case, application of an electromagnetic field to a powder compact results in a direct increase in the driving force for densification and an increase in densification kinetics. Elsewhere, the grain boundary can provide a significant contribution to microwave non-thermal effect on densification.

To go further in our discussion, the favorable effect of microwave field on densification seems not to be a plausible reason for its effect on microstructural evolution in the present work. Otherwise, the grain size-density relationship for microwave and conventionally sintered samples should evidence a difference in each case of alumina. It at least indicates that grain size is not only dependent on the maximal sintering temperature.

\section{Conclusions}

In the present work, our first attention has been paid to the calibration of temperature measurement for radiation pyrometer. By using three heating rates, two reference materials, and under exactly the same conditions as in all real microwave experiments, this calibration provided a reliable temperature measurement in microwave sintering. Afterwards, our effort was especially focused on the influence of the powder natures ( $\mathrm{MgO}$ doping level and specific surface area) on the grain growth, densification thermodynamics and kinetics.

Direct comparison of densification behavior under identical experimental conditions between conventional and microwave sintering demonstrated that, microwave heating results in a significant decrease in the sintering temperature as well as an enhanced densification. These favorable effects on densification could be more important due to the existence of $\mathrm{MgO}$ dopant or a decrease of particle size. With regard to grain-growth trajectories in the whole sintering stage, there is no noticeable difference for $\mathrm{MgO}$ doped or fine-grained samples sintered by any of the heating methods or thermal cycles, whereas a relatively remarkable gap exist for undoped $6 \mathrm{~m}^{2} / \mathrm{g}$ alumina sintered by different modes. This grain growth retardation effect has been attributed to the fine porosity retention induced by microwave field at this point, but not the local over-heating at grain boundaries. And these residual fine pores at grain boundaries allow inhibiting grain-boundary movement due to pinning effect.

In terms of thermodynamics, the significant reduction of apparent activation energy values in the intermediate stages of microwave sintering as compared to conventional sintering when the grain-growth trajectory was not changing notably, suggests that, the electromagnetic field could provide an additional driving force for densification. Furthermore, the mechanism(s) controlling the densification of alumina during microwave heating have been proposed. The grain growth exponent $n$ varied from 4 to 3 as the powder specific surface area increased from 6 to $19 \mathrm{~m}^{2} / \mathrm{g}$ under microwave sintering. Besides the hypothesis of the microwave induced electromagnetic pressure, this phenomenon may suggests that microwave-assisted densification of fine-grained alumina is controlled by in-series "interface-reaction/grain-boundary diffusion" mechanism. But either way, grain-boundary diffusion has been always enhanced by microwave non-thermal effect, and application of an electromagnetic field to powder compact results in a direct increase in densification kinetics.

\section{Acknowledgements}

This work was financially supported by the French National Research Agency under Grant no.: ANR-11-BS08-0014. The authors wish to express their gratitude towards Prof. Philippe Boullay at ENSICAEN for his support about the TEM image in this paper, and Prof. Claude Carry at University of Grenoble for his valuable suggestions.

\section{References}

1. Agrawal D, Chen JP, Hu P, Hurt L, Cherian K. Microwave energy applied to processing of high-temperature materials. Am Ceram Soc Bull 2008;87:39-44

2. Agrawal DK. Microwave processing of ceramics. Curr Opin Solid State Mater Sci 1998;3:480-5

3. Badev A, Heuguet R, Marinel S. Induced electromagnetic pressure during microwave sintering of $\mathrm{ZnO}$ in magnetic field. J Eur Ceram Soc 2013:33:1185-94.

4. Wang J, Binner J, Vaidhyanathan B. Evidence for the microwave effect during hybrid sintering. J Am Ceram Soc 2006;89:1977-84.

5. Rybakov KI, Olevsky EA, Krikun EV. Microwave sintering: fundamentals and modeling. J Am Ceram Soc 2013;96:1003-20.

6. Raj R, Cologna M, Francis JSC. Influence of externally imposed and internally generated electrical fields on grain growth, diffusional creep, sintering and related phenomena in ceramics. J Am Ceram Soc 2011;94:1941-65.

7. Santanach JG, Weibel A, Estournès C, Yang Q, Laurent C, Peigney A. Spark plasma sintering of alumina: study of parameters, formal sintering analysis and hypotheses on the mechanism(s) involved in densification and grain growth. Acta Mater 2011;59:1400-8

8. Zhou Y, Hirao K, Yamauchi Y, Kanzaki S. Densification and grain growth in pulse electric current sintering of alumina. J Eur Ceram Soc 2004;24:3465-70.

9. Langer J, Hoffmann MJ, Guillon O. Direct comparison between hot pressing and electric field-assisted sintering of submicron alumina. Acta Mater 2009;57:5454-65.

10. Zhao C, Vleugels J, Groffils C, Luypaert PJ, Van der biest O. Hybrid sintering with a tubular suscuptor in a cylindrical single-mode microwave furnace. Acta Mater 2000;48:3795-801.

11. Sudiana IN, Ito R, Inagaki S, Kuwayama K, Sako K, Mitsudo S. Densification of alumina ceramics sintered by using submillimeter wave gyrotron. $J$ Infrared Millimeter Terahz. Waves 2013;34:627-38.

12. Cheng JP, Agrawal D, Zhang YJ, Roy R. Microwave sintering of transparent alumina. Mater Lett 2002;56:587-92.

13. Golestani-fard F, Mazaheri M, Aminzare M, Ebadzadeh T. Microstructure evolution of a commercial ultrafine alumina powder densified by different methods. J Eur Ceram Soc 2011;31:2593-9.

14. Wang JX, Binner J, Pang YX, Vaidhyanathan B. Microwave-enhanced densification of sol-gel alumina films. Thin Solid Films 2008;516:5996-6001.

15. Zuo F, Carry C, Saunier S, Marinel S, Goeuriot D. Comparison of the microwave and conventional sintering of alumina: effect of $\mathrm{MgO}$ doping and particle size. J Am Ceram Soc 2013;96:1732-7.

16. Pert E, Carmel Y, Birnboim A, Olorunyolemi T, Gershon D, Calame J, et al. Temperature measurements during microwave processing: the significance of thermocouple effects. J Am Ceram Soc 2001;84:1981-6.

17. Żymełka D, Saunier S, Goeuriot D, Molimard J. Densification and thermal gradient evolution of alumina during microwave sintering at $2.45 \mathrm{GHz}$. Ceram Int 2013;39:3269-77. 
18. Żymełka D, Saunier S, Molimard J, Goeuriot D. Contactless monitoring of shrinkage and temperature distribution during hybrid microwave sintering. Adv Eng Mater 2011;13:901-5.

19. Mendelson MI. Average grain size in polycrystalline ceramics. J Am Ceram Soc 1969;52:443-6.

20. Zuo F, Badev A, Saunier S, Goeuriot D, Heuguet R, Marinel S. Microwave versus conventional sintering: estimate of the apparent activation energy for densification of $\alpha$-alumina and zinc oxide. J Eur Ceram Soc 2014;34:3103-10.

21. Xie ZP, Yang JL, Huang Y. Densification and grain growth of alumina by microwave processing. Mater Lett 1998;37:215-20.

22. Zuo F, Saunier S, Meunier C, Goeuriot D. Non-thermal effect on densification kinetics during microwave sintering of $\alpha$-alumina. Scr Mater 2013; 69:331-3.

23. Greskovich C, Brewer JA. Solubility of magnesia in polycrystalline alumina at high temperatures. J Am Ceram Soc 2001;84:420-5.

24. Kang SGL. Sintering: densification, grain growth and microstructure. first ed. Oxford, UK: Elsevier Butterworth-Heinemann; 2005.

25. He Z, Ma J. Densification and grain growth during interface reaction controlled sintering of alumina ceramics. Ceram Int 2001;27:261-4.
26. Wang J, Raj R. Estimate of the activation energies for boundary diffusion from rate-controlled sintering of pure alumina, and alumina doped with zirconia or titania. J Am Ceram Soc 1990;73:1172-5.

27. Coble RL. Sintering crystalline solids. I. Intermediate and final state diffusion models. J Appl Phys 1961;32:787-92.

28. Ghosh S, Chokshi AH, Lee P, Raj R. A huge effect of weak dc electrical fields on grain growth in zirconia. J Am Ceram Soc 2009;92:1856-9.

29. Johnson DL. Microwave-heating of grain-boundaries in ceramics. J Am Ceram Soc 1991;74:849-50.

30. Bykov YV, Egorov SV, Eremeev AG, Rybakov KI, Semenov VE, Sorokin AA, et al. Evidence for microwave enhanced mass transport in the annealing of nanoporous alumina membranes. J Mater Sci 2001;36:131-6.

31. Panichkina VV, Shevchenko EA, Bykov YV, Eremeev AG. Compaction and grain growth in alumina ceramics under microwave sintering. Powder Metall Met Ceram 1997;36:359-63.

32. Rybakov KI, Semenov VE. Possibility of plastic deformation of an ionic crystal due to the nonthermal influence of a high-frequency electric field. Phys Rev B: Condens Matter 1994;49:64-8.

33. Ashby MF. On interface-reaction control of Nabarro-Herring creep and sintering. Scr Mater 1969;3:837-42. 